\title{
Journal publication success of German business researchers: does gender composition and internationality of the author team matter?
}

\author{
Martin Eisend $^{1} \cdot$ Pakize Schuchert-Güler $^{2}$
}

Received: 26 May 2014/Accepted: 1 July 2015/Published online: 21 July 2015

(C) The Author(s) 2015. This article is published with open access at Springerlink.com

\begin{abstract}
The authors analyze whether publication success of journal articles by authors from German-speaking countries is related to gender composition and internationality of the author team. The database for the analysis covers 7,464 articles that were published in peer-reviewed journals between 2008 and 2012 and that were (co-)authored by business researchers from German-speaking countries. The articles were ranked according to the quality of the journal an article was published in, using three prominent journal rankings in business research. The findings indicate that journal publication success is significantly higher in predominantly male and predominantly international author teams, and this relationship is even stronger the more selective the ranking is. The findings also indicate an interaction between gender composition and internationality. The findings vary across disciplines in business research depending on the average share of female coauthors in a discipline. Since the substantial differences in publication success for author teams that vary in gender composition are rather small and we even find a tendency of female authors to be more productive than male authors, these findings show that providing equal opportunities for female and male researchers that is a goal in its own right does not hurt science but can benefit research outcomes.
\end{abstract}

Electronic supplementary material The online version of this article (doi:10.1007/s40685-015-0019-y) contains supplementary material, which is available to authorized users.

Martin Eisend

eisend@europa-uni.de

Pakize Schuchert-Güler

psg@hwr-berlin.de

1 European University Viadrina, Große Scharrnstraße 59, 15230 Frankfurt (Oder), Germany

2 Berlin School of Economics and Law, Berlin, Germany 
Keywords Journal publication success · Gender composition · Internationality · Business research

\section{Introduction}

Business research at universities in German-speaking countries has traditionally been conducted by men (Krell 2005). While the first habilitation in business research is dated 1903, it took forty years till the first female researcher in the field submitted a habilitation and was appointed full professor in 1942. It took another thirty years until the second woman was appointed full professor. In 2000, only $4.1 \%$ of all professors in the field of business research were female (Krell 2005). The percentage of women is increasing slowly but steadily. During the years 1992 to 2011, the share of female full professors in all academic fields in Germany has increased from 3.8 to $15.5 \%$ (Gemeinsame Wissenschaftskonferenz 2013).

Gender equality policy and governance structures are main drivers of this development. While the political means to create equal opportunities for both female and male researchers are subject to many political discussions (e.g., Dalhoff 2013; European Commission 2013), the question whether an increase in the share of female researchers as a result of this means benefits the scientific endeavor and even increases research performance is largely neglected in these discussions. In this study, we look at journal publication success as one indicator of research performance and we investigate whether successful journal publications are related to the gender composition of the author team. We further look at the internationality of the author team and we investigate whether this internationality is related to journal publication success and whether this relationship depends on the gender composition of author teams. By looking at all journal articles published by authors from German-speaking countries between 2008 and 2012, we answer the following research question: Is journal publication success related to the gender composition and internationality of an author team?

In this study, we focus on the quality of research, that is, on journal publication success instead of productivity of individual researchers as has been done in many prior studies. Both measures are related, but they are not the same, because research productivity refers mainly to quantity of publications, while the success of a published article refers to its quality. We focus on the quality of research, because it is a major evaluation criterion during the career of scholars, in particular for early stage scholars: Journal publication success is used when evaluating cumulative doctoral dissertations, habilitations, and tenure appointments (Schrader and HennigThurau 2009).

The study contributes to the literature and to practice in several ways. First, the study provides findings on the role of author team composition for successful journal publications of business researchers in German-speaking countries. This knowledge is new and unique as it provides insights from a cultural and disciplinary context, for which such findings are not yet available. Second, by analyzing the combined effect of gender composition and internationality in author teams, we describe which author teams are most successful in terms of publication success, 
thus contributing to the research on diversity and research performance. Third, by analyzing the findings across different disciplines in business research, we are able to identify gender and nationality differences and their relationship with publication success in these disciplines, which have not been revealed so far.

The outline of the paper is as follows. First, we provide a conceptual background and an overview of prior research regarding gender composition and internationality of author teams and journal publication success. Then, we describe the database used for this study, the measures, and analytical procedure. We present our results and we provide a brief discussion of the findings, conclusions, and implications for research, for scholars, and the academic community in German-speaking countries.

\section{Gender composition and internationality of author teams and journal publication success}

\subsection{Gender composition of author teams and publication success}

Gender composition of author teams refers to the share of either female or male authors in an author team. Few studies have focused on the relationship between publication success and gender composition of author teams and found either a negative relationship between increasing shares of female authors and publication success (Breuning and Sanders 2007; Prozesky and Boshoff 2012) or no relationships between both variables (Barrios et al. 2013; Haslam et al. 2008; Tower et al. 2007). The inconsistent findings related to author teams' gender composition are in line with the inconsistency of the great many of findings describing the research productivity of either female or male authors. For instance, prior research found that men publish significantly more research in some of the highest rated business journals (Brooks et al. 2014). Other studies show that men reach a higher number of publications in their career than women, but this difference in research productivity declined over time (Bentley 2011; Xie and Shauman 1998). Further research indicates that the performance gap between male and female researchers in the social sciences has disappeared in the younger generation and in some areas young female researchers even outperform young male researchers in terms of productivity (van Arensbergen et al. 2012).

In this study, we focus on the quality of research, that is, on journal publication success and we look at the role of gender composition of author teams for the success of papers by authors from German-speaking countries. To specify the possible relationship between gender composition of author teams and publication success, we include internationality of author teams as an additional explanatory factor that can interact with the effect of gender composition as described in the following.

\subsection{Internationality of author teams and publication success}

Internationality refers to the share of either national or international authors in an author team. Previous research has shown a positive relationship between an 
increasing share of international authors in author teams and publication success. Collaboration with researchers from outside a country increases the impact factor of the journal the collaboration articles are published in and the citations to articles (He et al. 2009). German business researchers prefer to collaborate with US authors (Eisend and Schmidt 2014) and research in other areas has shown that the collaboration with US authors compared to other international authors can increase publication success as measured by the impact factor of the journal the articles are published in (Vogel 1997). Completely homogenous teams with respect to nationality, that is, researchers from a single country, profit from enhanced knowledge and skills (in terms of theoretical and methodological knowledge, but also language proficiency) that is provided by researchers from other countries (Van Rijnsoever and Hessels 2011). Increasingly international teams can produce a broader range of ideas and information as a result of different backgrounds, experiences, and education as well as values and beliefs. The integration of diverse experiences broadens alternatives, which leads to innovative solutions and resolves complex tasks (Nielsen and Nielsen 2013). A broader knowledge base also improves the understanding and acquisition of new knowledge.

Since women, on average, tend to collaborate less with foreign authors than men (Lemoine 1995), because they have smaller networks of contacts (Renzulli et al. 2000) and are, on average, less willing to travel abroad (Lewison 2001), the female authors' experience with internationality is smaller and the question arises whether female authors in author teams will benefit from international experience in the same way as predominantly male author teams. The combined effect of gender composition and internationality in author teams on journal publication success has been investigated only sparsely in three studies from psychology (Barrios et al. 2013), invasion ecology (Prozesky and Boshoff 2012), and from a multidisciplinary perspective (Bentley 2011). The findings are not significant except for the study by Prozesky and Boshoff (2012) who have looked at publications by ecology researchers from South Africa and found that the relationship between international co-authorship and citations is stronger for male than for female researchers. One of the aims of the current study is to investigate this relationship in a different context by looking at articles from business researchers in German-speaking countries.

\section{Methods}

\subsection{Data}

Data are taken from the 2012 "Handelsblatt"-ranking database ${ }^{1}$. Handelsblatt is a daily German newspaper that publishes rankings of all business researchers in German-speaking countries based on their publication output. The 2012 ranking

\footnotetext{
${ }_{1}$ Data were provided by the KOF (Konjunkturforschungsstelle) at ETH Zürich. KOF prepares and analyzes data for the Handelsblatt ranking that are provided by the Forschungsmonitoring platform. We received the data after signing a confidentiality agreement. The data set covers all data that are collected by Forschungsmonitoring. That is, our analysis considers all researchers in German-speaking countries including those who refused to have their individual ranking results published.
} 
measures the publication output of researchers by taking into account all articles the researchers have published in peer-reviewed academic journals or that have been accepted for publication by these journals between 2008 and 2012. The journal list covers around 950 journals mainly from business, but also from economics, and related fields (e.g., psychology). This extensive list minimizes the risk of a selection bias.

The original dataset covers 10,627 articles. Because articles that are published by more than one author from German-speaking countries appear more than once, we excluded duplicates, which result in a dataset of 7,471 different articles. For all articles, we coded characteristics of the author team, that is, the percentage of female authors and the percentage of international authors in the team. The final dataset includes 7,464 articles, because we could not retrieve necessary demographic information of all authors for seven articles.

\subsection{Measures and variables}

We apply four different publication success measures as dependent variables. We use two measures that are provided by the Handelsblatt ranking. Each article is assigned a journal score for the journal the article was published in (cf., Schläpfer and Storbeck 2012). The journal scores range from .1 (lowest ranked journals) to 1.0 (highest ranked journal). Journals with a score of .7 and higher are considered A journals (top/first and second-tier journals), and journals with a score of 1.0 are considered $\mathrm{A}+$ journals (top/first-tier journals). Three major journal rankings provide the input for these journal scores: the 2012 ranking by the German Academic Association for Business Research (VHB-JOURQUAL 2.1), the 2006 list by the Erasmus Research Institute of Management (EJL), and the 2011 SSCI impact factor as provided by Web of Science. Our first measure "journal score" is a continuous measure of the quality of a journal an article was published in, ranging from lowest ranked to highest ranked journal. Second, publication in an A and A+ journal indicates whether an article was published in a first- or second-tier journal; in total, 84 journals are ranked as A and A+ journals. We used two other influential rankings that classify leading journals in business research: the Financial Times research ranking (FT) classifies 45 journals as leading and the UT Dallas research ranking (UTD) classifies only 24 journals as top journals. Hence, the success measures become more exclusive and selective when moving from journal score to $\mathrm{A} / \mathrm{A}+$ journal publications to the Financial Times ranking and to the UT Dallas ranking.

The main independent variables are the share of female authors and the share of international authors in the author team. Authors were coded as national according to the list of researchers from German-speaking countries provided by the Handelsblatt. The Handelsblatt list includes all researchers who are from German-speaking countries or work as researchers in German-speaking countries. We also include the publication year of an article and the number of authors as control variables. The number of authors is positively related to the success of publications (Aksnes 2003; Wuchty et al. 2007). 
Publication success is discipline-specific: men have higher publication success in particular fields, while in some research fields and disciplines female researchers have higher publication success than their male counterparts (Duch et al. 2012). Business research is a field with several disciplines such as accounting, finance, marketing, management, operations research and production, or information systems. These disciplines differ in terms of publication practices and standards (Eisend and Schmidt 2014). To investigate differences between disciplines, we assigned each article to a particular discipline in business research based on the orientation of the journal in which the article was published. We used the article title for coding if a journal provides a platform for articles from different fields (e.g., Management Science, Journal of Business Research). We distinguish between six different disciplines according to the classification of the journal Business Research: Accounting, finance, marketing, management, operations research/production, and information systems. Although not included in the Business Research classification, we added information systems due to the large number of articles in the database that were assigned to this discipline. Articles that could not be assigned to either discipline are captured by the base category "other". Table 1 provides an overview of the variables that were used in the analysis, their description and coding.

Table 1 Variables used in the analysis

No Variable Description and coding

Dependent variables

1 Journal score

$2 \mathrm{~A} / \mathrm{A}+$ journal publication

3 Financial times

4 UT Dallas

Independent variables

$3 \%$ Female

$4 \%$ International

5 Number of authors

6 Publication year

7 Discipline
Continuous variable that indicates the quality of a journal; measured by journal scores that range from 0.1 (lowest quality) to 1.0 (highest quality) as provided by the Handelsblatt ranking

Dummy variable that indicates whether an article is published in a first- or second-tier journal (as measured by journal score of $0.7-1.0$ in the Handelsblatt ranking)

Dummy variable that indicates whether an article is published in a journal that is listed by the Financial Times research ranking

Dummy variable that indicates whether an article is published in a journal that is listed in the UT Dallas research ranking

Percentage of female authors in the author team

Percentage of international authors in the author team. Authors were coded as national according to the list of researchers from German-speaking countries provided by the Handelsblatt. The Handelsblatt list includes all researchers who are from German-speaking countries or work as researchers in German-speaking countries

The number of authors of an article

Publication year of an article [computed as publication year-2008

(=earliest publication year)]

We assigned each article to a particular discipline in business research according to the classification of Business Research: Accounting, finance, marketing, management, operations research/production, and information systems. Articles that could not be assigned to either discipline are captured by the base category "other" 


\subsection{Analytical procedure}

To test the influence of the independent variables on journal score, we apply a linear regression analysis; to test the influence on the remaining success measures (A/A+ journal publication, UT Dallas, and Financial Times), which are dummy variables, we apply logit regression. For each dependent variable, we run two regression models. Model 1 includes only main effect predictors; model 2 adds the interaction term between percentage of female authors and percentage of international authors. We mean centered the variables that are used for the interaction term.

Table 2 provides the correlation matrix of the data. Neither the correlations nor collinearity statistics indicate collinearity problems for those variables that go into one model. This is supported by the maximum VIF value of 1.62 across all models. If a model indicates heteroscedasticity (i.e., Breusch-Pagan test is significant), we use robust standard errors. We tested several functional forms (logarithmic, quadratic, and exponential) for the continuous variables. The linear form provides the best fit, both graphically and statistically for the variable publication year. The logarithmic function seems to provide a better fit graphically for the variable number of authors than the linear function, because the number of authors is skewed. After adding the logarithmic function to the regression models, however, the model fit does not improve. Therefore, we decided to work with the linear function.

\section{Results}

\subsection{Descriptive analysis}

Table 3 provides some descriptive information on the articles for the whole field and for each discipline. The figures provide information on differences between disciplines. The highest percentage of female authors in an author team is found in marketing and the lowest percentage in information systems. As for the internationality of author teams, the most international author teams are found in operations research/production, the least international teams are found in accounting. These differences are partly related to the research subjects of the various disciplines: in accounting, the topic of a paper is more likely to have a national focus and authors team, therefore, with authors from the same country. The success measures indicate that operations research/production reaches the highest scores according to the Handelsblatt ranking and information systems reaches the lowest scores. Management reaches the highest percentage of top publication in the Financial Times ranking, while marketing reaches the highest percentage in the UT Dallas ranking.

\subsection{Regression analysis results for the whole field of business research}

Table 4 provides the regression estimation results for the whole data set. The model fit statistics indicate a significant model fit for all models. The findings across model 


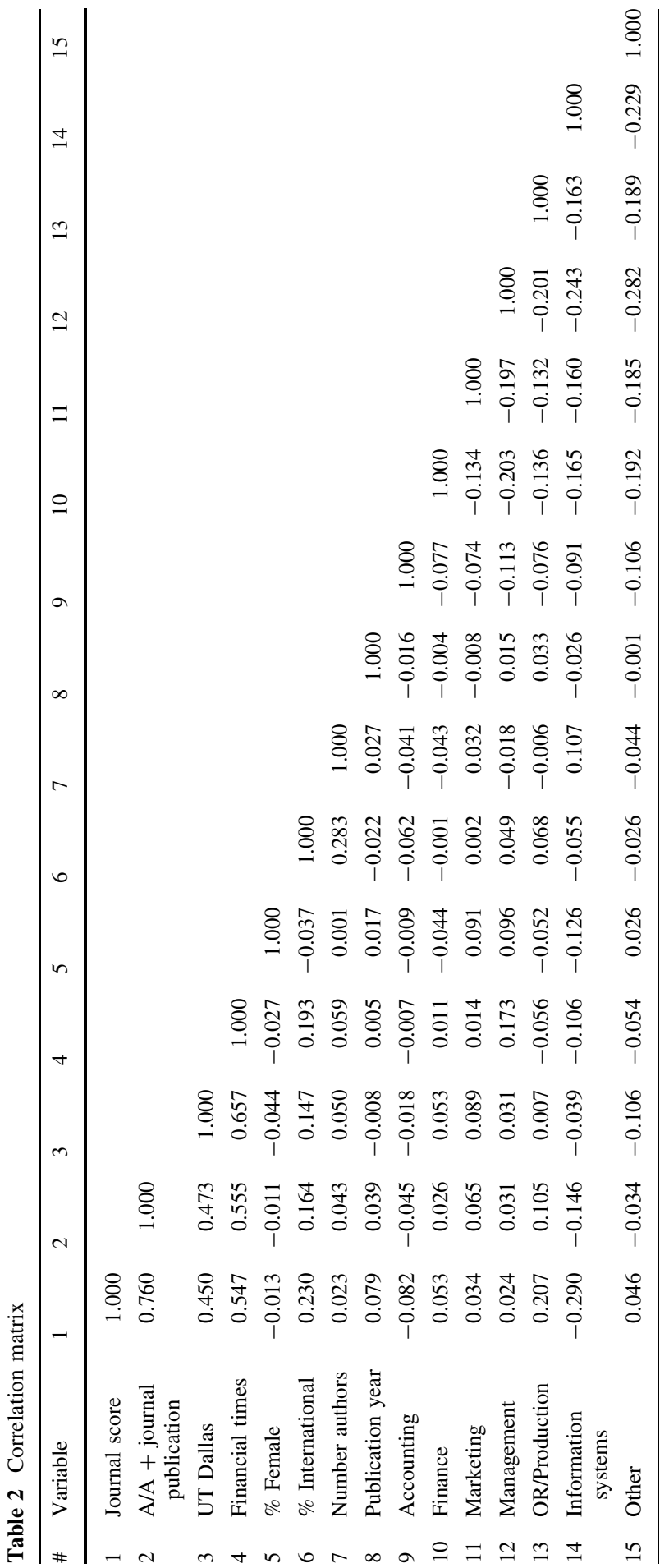




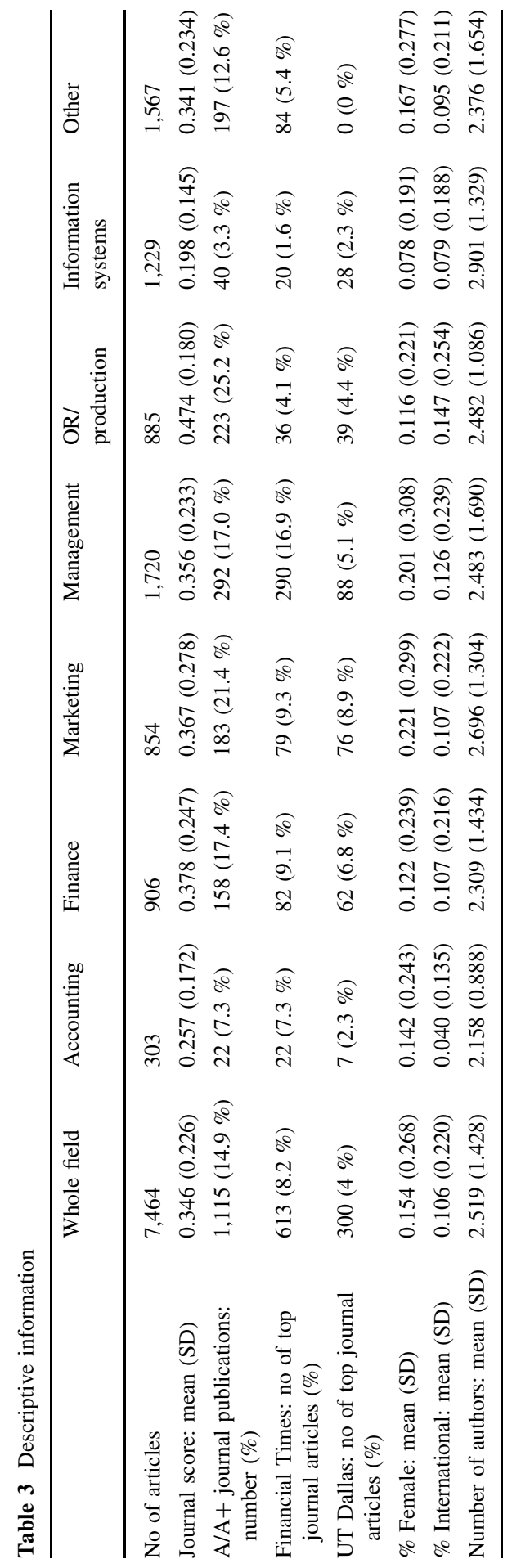




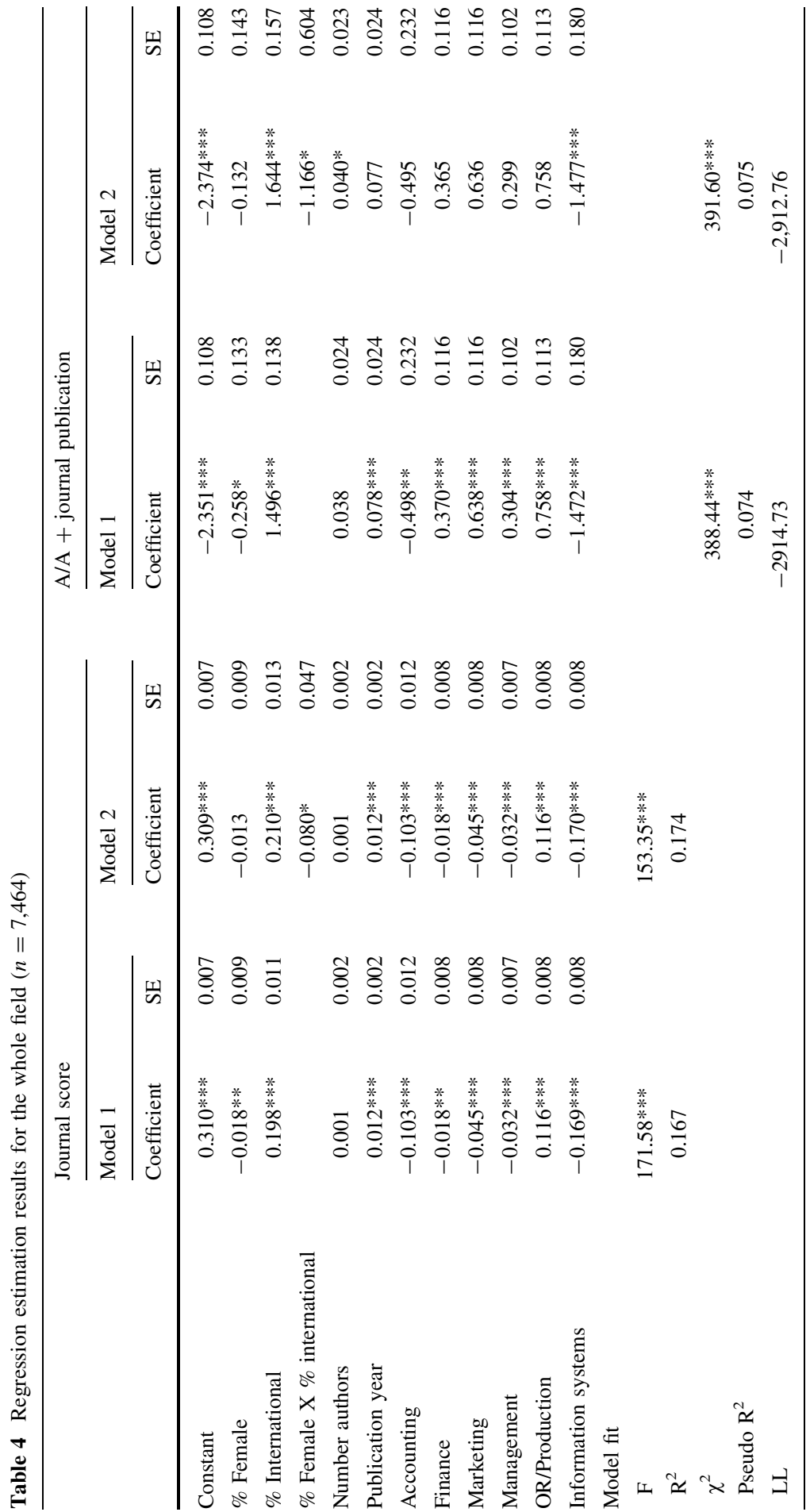




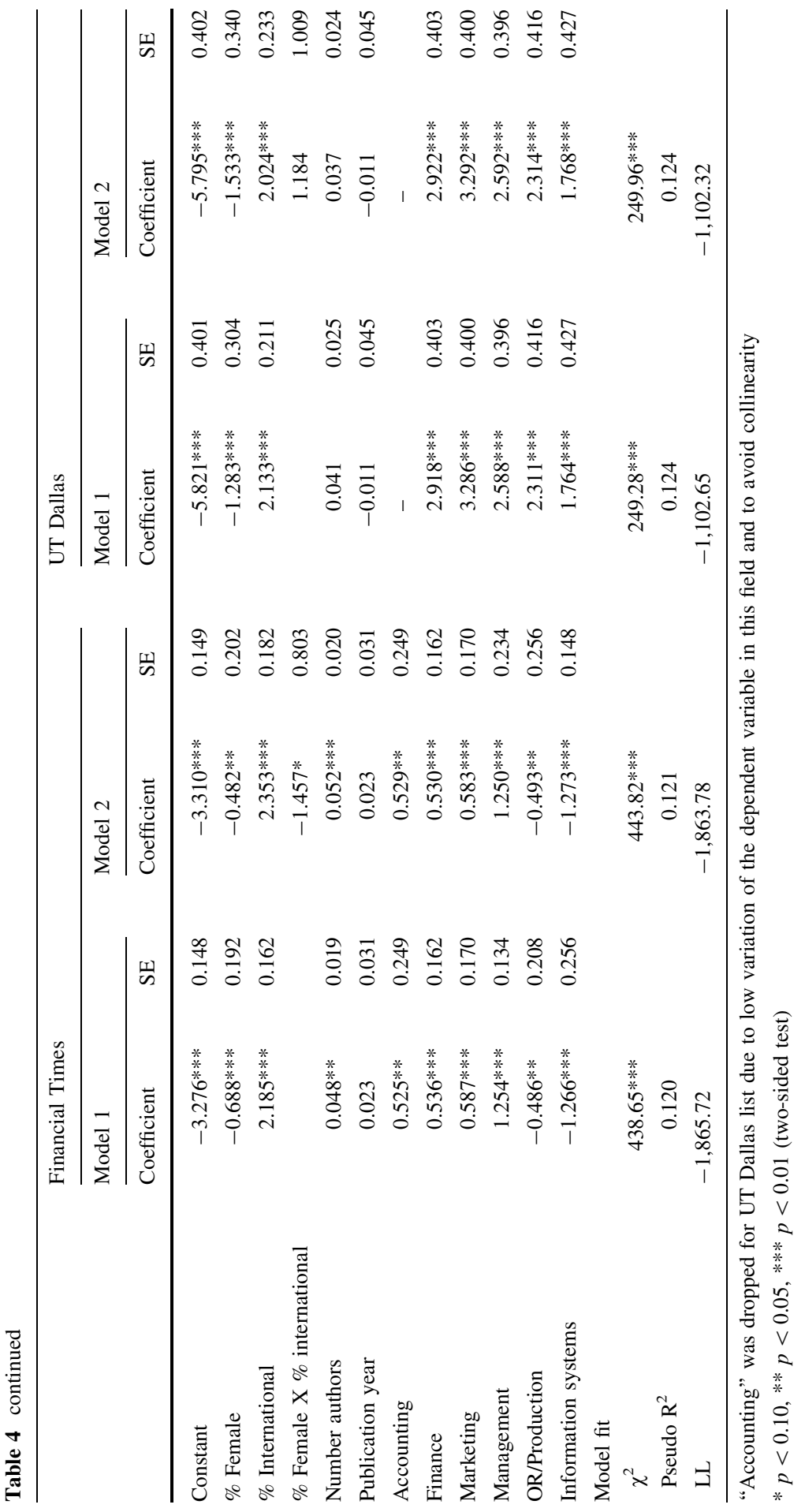


1 and model 2 for each publication success measure show only minor changes in the size of the coefficients, which support the robustness of the models.

The main effects show consistently that the percentage of international coauthors in an author team is positively related to publication success. This effect tends to become larger, the more exclusive and selective the ranking gets. The coefficients indicate that a mixed team (half national and half international) compared to a national team is related to an increase of the journal score by .1 journal scores, an increase in the odds to get published in an A/A+ journal by two percent, an increase in the odds to get published in journals of the FT list by more than four percent, and an increase in the odds to get published in the journals of the UTD list by more than three percent.

The share of female co-authors is negatively related to publication success. This gender effect becomes insignificant and thus irrelevant once the interaction effect is added for journal score and $\mathrm{A} / \mathrm{A}+$ journal publications. That is, the relationship between gender composition and publication success is conditional, as can be seen from the interaction graphs (Figs. 1, 2, 3): an increasing share of international authors is related to higher publication success, but the increase is stronger, the higher the share of male authors in the team. This interaction effect is not significant for the most exclusive and selective ranking, the UT Dallas ranking, where the negative effect of gender composition remains. The coefficient in the UT Dallas model indicates that a mixed team (half female and half male) compared to a male author team is related to a decrease in the odds to get published in the journals of the UTD list by less than two percent. Similarly, a mere female team compared to a mere male team is related to a decrease in the odds to get published in the journals

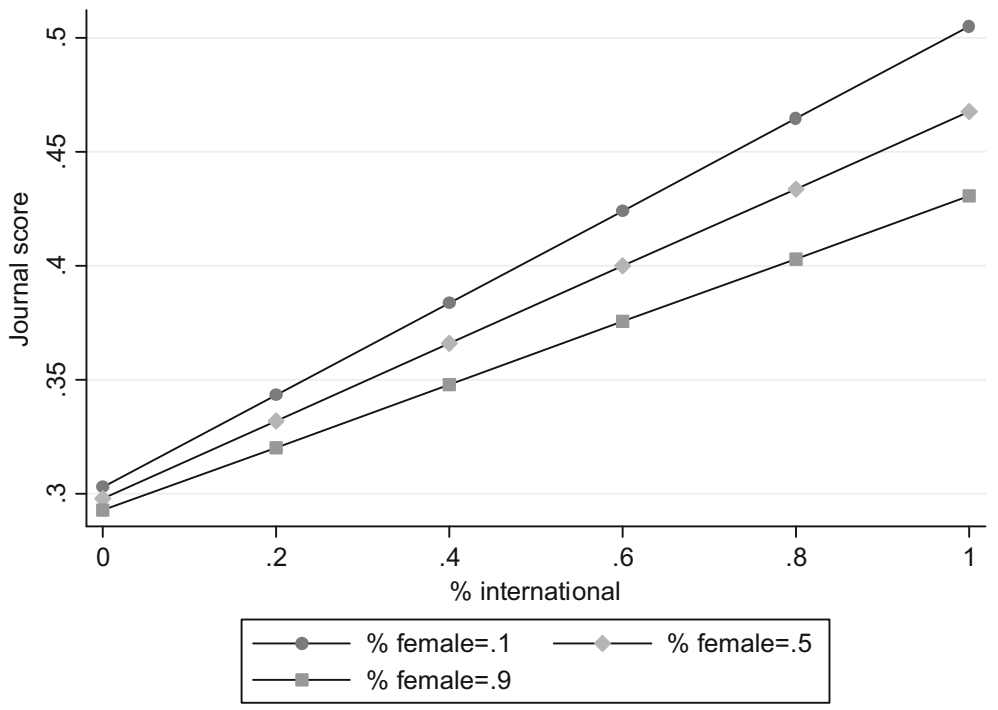

Fig. 1 Interaction effect of $\%$ female and \% international (journal score) 


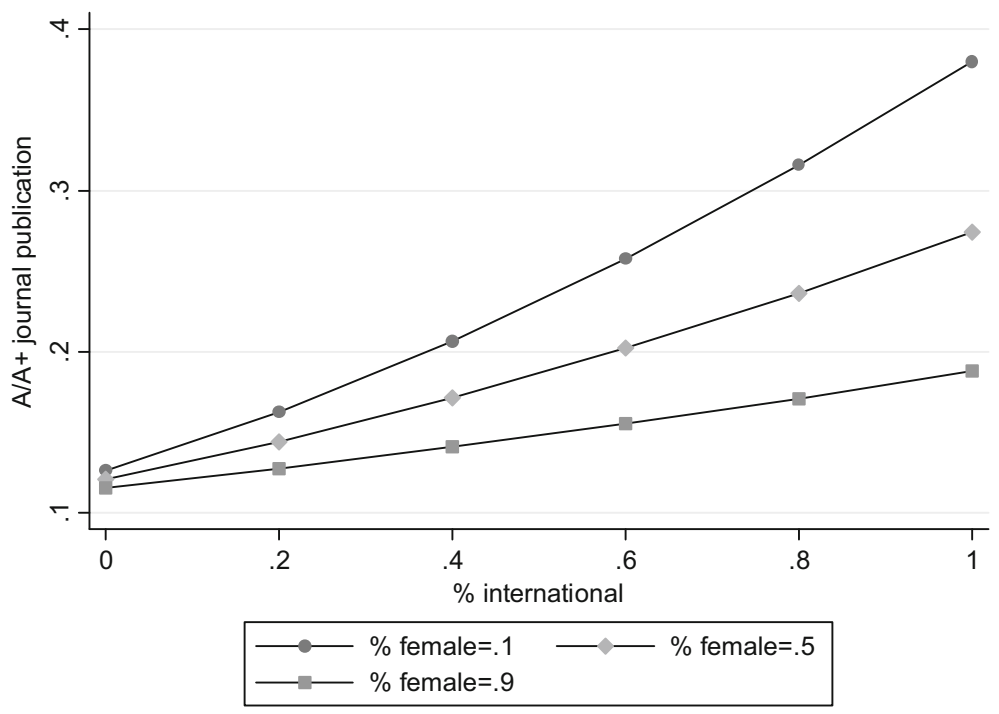

Fig. 2 Interaction effect of $\%$ female and $\%$ international (A/A+ journal publication)

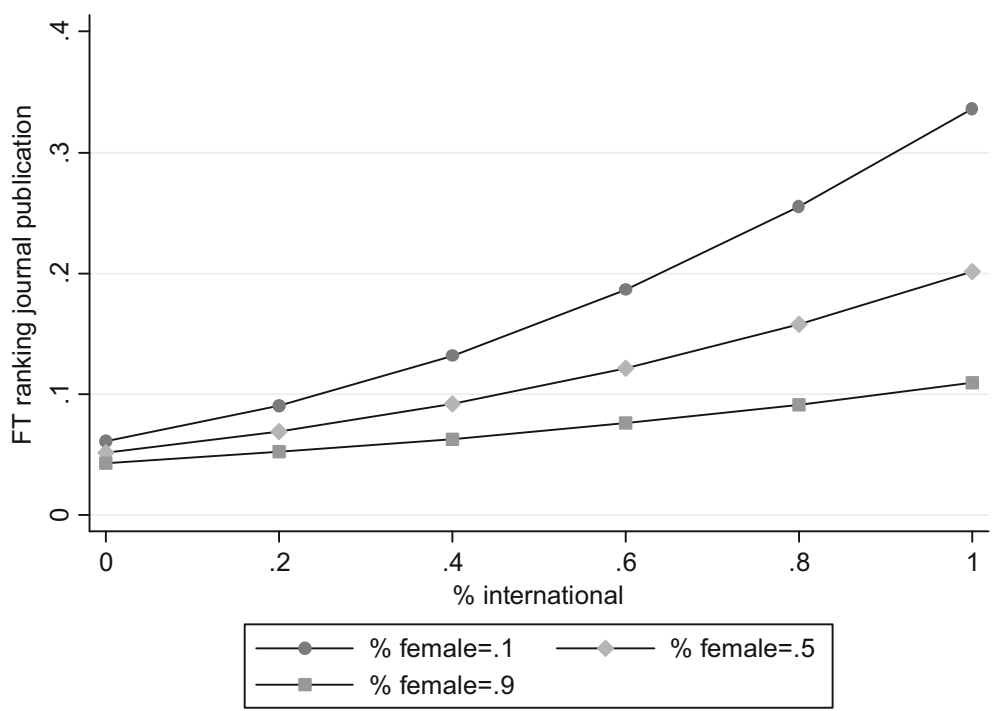

Fig. 3 Interaction effect of $\%$ female and $\%$ international (Financial Times ranking)

of the UTD list by less than four percent. That is, the substantial gender composition effects are actually rather small and negligible for any policy implications.

In addition, we find that the number of co-authors is not related to publication success except for publications that are listed in the Financial Times ranking. Publication year is positively related to publication success for the less selective 
success measures journal score and A/A+ journal publications. Table 4 further indicates that the effects differ across disciplines. When the ranking gets more selective, the disciplines finance, marketing, and management turn out to be positively related to publication success.

\subsection{Regression analysis results for each discipline}

In an additional analysis that is largely explorative in nature, we apply the regression models separately to each of the six disciplines. The estimation results of all models are provided in the appendix. The findings support the positive relationship of internationalization of author teams with publication success in almost all models.

We find a negative relationship between share of female authors in author teams and journal publication success in marketing and management, but these effects are conditional as indicated by the significant interaction effects between gender composition and internationality. We find consistent patterns of the interaction effect in finance (for the dependent variable journal score) and in management (for journal score, A/A+ publication, and Financial Times). The interaction effect is significant in marketing as well (for $\mathrm{A} / \mathrm{A}+$ publication, Financial Times, and UT Dallas), but the effect is reversed: author teams that are predominantly female benefit most from high shares of international authors.

The control variables show varying effects across the disciplines and rankings. Publication year increases success mainly for success measures from less exclusive rankings (Handelsblatt), but less so for the more exclusive rankings (FT and UTD). The number of authors is a success factor primarily in finance and management.

\section{Discussion}

The current study provides several insights. First, the study provides findings on the role of author team composition and its relationship with successful journal publications of business researchers in German-speaking countries. Predominantly, male and international author teams have significantly higher journal publication success, and this relationship is even stronger the more exclusive the ranking gets. This knowledge is new and unique for the particular cultural and disciplinary context. The findings add to the research on international research collaboration and co-authorship by corroborating the positive relationship between internationality in author teams and research performance revealed by previous studies that have been conducted in other fields and in other countries.

Second, the finding about the relationship between gender composition and journal publication success is conditional as indicated by the interaction of internationality and gender composition in author teams and their relationship with publication success. The negative relation between the share of female authors in an author team and the corresponding paper's publication success is apparently driven 
by author teams that at the same time have a high share of international authors. This interaction effect qualifies the negative relationship between the share of female authors in author teams and publication success. That is, the negative relationship disappears once we take into account that author teams differ along both dimensions: internationality composition and gender composition. Furthermore, the findings show that the publication success of mainly national author teams is not related to the gender composition of the author team.

Third, by analyzing the findings in different disciplines in business research, we are able to identify differences in gender composition and internationality of author teams and their relationship with publication success across different disciplines. While internationality in author teams is related to publication success in almost all fields, gender composition is not. We find interaction effects similar to the whole field for finance and management, but a reversed interaction effect in marketing, where author teams with high shares of female authors benefit more from increasing internationalization than male-dominated author teams. Marketing is the field with the highest percentage of female researchers who (co-)author a paper, indicating a stronger position of female authors and possibly a longer tradition of female researchers in this discipline. Hence, the effects found in the whole field of business research can differ across disciplines depending on the average share of female coauthors in a discipline.

The aim of this study was to answer the question: "Is journal publication success related to the gender composition and internationality of an author team?" and to find out whether an increasing share of female researchers contributes to publication success in the field. While our findings clearly indicate that increasing internationality benefits research by increasing the quality of publications, the share of female researchers has small effects. Even if we find some significant differences for gender composition, the substantial gender differences are very small. In fact, the findings in a discipline such as marketing even indicate that once the share of female researchers has increased, female researchers can benefit even more from increasing internationalization in author teams than male researchers. The reasons might be manifold, such as better networks, or stronger influence by female researchers on structures and processes in academia. The findings are in line with prior research of quality of publication success of male and female researchers: if quality is measured by citations, some studies found comparable or even higher figures for female researchers (Aksnes et al. 2011; Penas and Willett 2006). While the quality of publications seems barely to be affected by gender composition, the quantity of publications seems to indicate a productivity advantage of female researchers. The share of female authors from German-speaking countries of the papers published between 2008 and 2012 in our dataset $(14 \%)$ is actually slightly higher than the share of female members in the German Academic Association for Business Research as of 2010 (12\%), indicating a higher productivity of female researchers compared to male researchers from German-speaking countries. As a result, the findings in this study indicate that an increasing share of female researchers in business research in German-speaking countries does not hurt research success of the field. While providing equal opportunities is a goal in its own right, it can also benefit the field. Hence, the findings underline the importance of the measures that 
are already taken to increase equal opportunities for female and male researchers, which result in an increase in the share of female researchers in our field.

The study provides an exemplary approach for many other countries. Gender disparities in academia and related patterns of journal publication success vary across countries: Sugimoto (2013) shows that overall men dominate scientific production, but South American and Eastern European countries demonstrate greater gender parity than other countries and nine countries in the world had female dominance in terms of share of co-authors. The current study looks at business researchers in German-speaking countries (Germany, Austria, and German-speaking part of Switzerland). The academic system in these countries is in a phase of transition where increasing application of gender equality measures changes gender distribution in academia. In addition, the academic system is driven by increasing internationalization. As such the cultural context of our study is a suitable representative of many other countries that strive for same opportunities for female and male researchers and for increasing internationality in academia.

This study is not without limitations. A major limitation refers to the journal publication success measures that we use to assess academic performance. Journal publication success is only one indicator of academic performance next to excellence in teaching, receiving grants, job offers from prestigious schools, successful industry cooperation, etc. Although journal-ranking-based performance indicators have been criticized for a variety of reasons (e.g., Albers 2009; Rost and Frey 2011), successful journal publications became and continue to be an important evaluation criterion for academician's careers, promotion of scholars, and prestige of schools. Thus, identifying differences in journal publication success of author teams of varying diversity is important for scholars and contributes to the discussion on promoting equal opportunities for both gender and internationalization in academia.

Another limitation of this study refers to the specific dataset of this study. The Handelsblatt ranking is one of many attempts to rank journals along their quality. The analysis of top journals that were either provided by the Financial Times list, by UT Dallas or by Handelsblatt, shows that the findings can differ, even if the major tendency in the results remains stable. Journal rankings are highly correlated, but are not fully consistent (Eisend 2011). In particular, the Handelsblatt ranking includes both national and international journals and thus considers a broader spectrum of publication activities of German-speaking researchers than other rankings. The Handelsblatt ranking is based on three major rankings, among them the VHB journal list that became the major criterion to assess journal publication success in Germany (Schrader and Hennig-Thurau 2009). Hence, the findings are certainly meaningful for business researchers in German-speaking countries, but it is important to note that the findings depend to some extent on the choice of a particular ranking. Furthermore, it should be kept in mind that a perfect journal ranking does not exist and that rankings need an ongoing evaluation by the community. Both the Handelsblatt ranking and the VHB journal list are updated on a regular basis to respond to the many concerns of the community.

A further limitation refers to the coding of data. Author teams differ in many more dimensions than just gender and internationality, with some of them 
presumably related to publication success, such as age, experience, or job position of the authors. Unfortunately, we were not able to code this information for the whole data set that covers more than 18,000 authors, because this information is not as readily available as information on gender and nationality. For the same reason, we were not able to differentiate between nationalities of international authors. Prior research indicates that German authors tend to collaborate with authors at US universities to increase publication success of their research (Eisend and Schmidt 2014), which raises the question whether publication is driven by collaboration with US researchers compared to collaborations with researchers from other countries.

A final limitation refers to endogeneity in our data. For instance, international coauthors might be more likely to collaborate with skilled and experienced researchers from German-speaking countries, and the positive relationship between internationality and publication success could reflect a German-speaking researcher's skills (Eisend and Schmidt 2014). Therefore, our regression results are descriptive and should not be interpreted in a causal way. Whether an article is written by a primarily national or primarily female author team is endogenous and does not necessarily imply that changing the composition of an author team changes the success of a journal article, too.

Open Access This article is distributed under the terms of the Creative Commons Attribution 4.0 International License (http://creativecommons.org/licenses/by/4.0/), which permits unrestricted use, distribution, and reproduction in any medium, provided you give appropriate credit to the original author(s) and the source, provide a link to the Creative Commons license, and indicate if changes were made.

\section{References}

Aksnes, Dag W. 2003. Characteristics of highly cited papers. Research Evaluation 12(3): 159-170.

Aksnes, Dag W., Kristoffer Rorstad, Fredrik Piro, and Gunnar Sivertsen. 2011. Are female researchers less cited? A Large-Scale Study of Norwegian Scientists, Journal of the American Society for Information Science and Technology 62(4): 628-636.

Albers, Sönke. 2009. Misleading rankings of research in business. German Economic Review 10(3): 352-363.

Barrios, Maite, Anna Villarroya, and Ángel Borrego. 2013. Scientific production in psychology: a gender analysis. Scientometrics 95(1): 15-23.

Bentley, Peter. 2011. Gender differences and factors affecting publication productivity among Australian university academics. Journal of Sociology 48(1): 85-103.

Breuning, Marijke, and Kathryn Sanders. 2007. Gender and journal authorshop in eight prestigious political science journals. PS, Political Science \& Politics 40(April): 347-351.

Brooks, Chris, Evelyn M. Fenton, and James T. Walker. 2014. Gender and the evaluation of research. Research Policy 43(6): 990-1001.

Dalhoff, Jutta. 2013. Hochschulische Gleichstellungspolitik 2013-eine kritisch-konstruktive Bilanz mit Perspektive(n). CEWS Journal 91: 1-82.

Duch, Jordi, Han T. Xiao, Marta Sales-Pardo Zeng, Filippo Radicchi, Shayna Otis, Teresa K. Woodruff, and Luís A. Nunes Amaral. 2012. The possible role of resource requirements and academic careerchoice risk on gender differences in publication rate and impact. PLoS One 7(12): e51332.

Eisend, Martin. 2011. Is VHB-JOURQUAL2 a good measure of scientific quality? Assessing the Validity of the Major Business Journal Ranking in German-Speaking Countries, Business Research 4(2): 241-274.

Eisend, Martin, and Susanne Schmidt. 2014. The influence of knowledge-based resources and business scholars' internationalization strategies on research performance. Research Policy 43(1): 48-59. 
Commission, European. 2013. She figures 2012. Statistics and Indicators: Gender in Research and Innovation.

Gemeinsame Wissenschaftskonferenz. 2013. Chancengleichheit in Wissenschaft und Forschung: 17. Fortschreibung des Datenmaterials (2011/2012) zu Frauen in Hochschulen und außerhochschulischen Forschungseinrichtungen, Bonn.

Haslam, Nick, Lauren Ban, Leah Kaufmann, Stephen Loughnan, Kim Peters, Jennifer Whelan, and Sam Wilson. 2008. What makes an article influential? Predicting Impact in Social and Personality Psychology, Scientometrics 76(1): 169-185.

He, Zi-Lin, Xue-Song Geng, and Colin Campbell-Hunt. 2009. Research collaboration and research output: a longitudinal study of 65 biomedical scientists in a New Zealand university. Research Policy 38(2): 306-317.

Krell, Gertraude. 2005. Betriebswirtschaftslehre und Gender Studies. Eine Einführung zu Geschichte und Gegenwart. In Betriebswirtschaftslehre und gender studies, ed. Gertraude Krell, 1-38. Wiesbaden: Analysen aus Organisation, Personal, Marketing und Controlling, Gabler.

Lemoine, W. 1995. Productivity patterns of men and women scientists in venezuela. Scientometrics 24(2): 281-295.

Lewison, Grant. 2001. The quantity and quality of female researchers: a bibliometric study of Iceland. Scientometrics 52(1): 29-43.

Nielsen, B.B., and S. Nielsen. 2013. Top management team nationality diversity and firm performance: a multilevel study. Strategic Management Journal 34(3): 373-382.

Penas, Celia Sánchez, and Peter Willett. 2006. Brief communication: gender differences in publication and citation counts in librarianship and information science research. Journal of Information Science 32(5): 480-485.

Prozesky, Heidi, and Nelius Boshoff. 2012. Bibliometrics as a tool for measuring gender-specific research performance: an example from South African invasion ecology. Scientometrics 90(2): 383-406.

Renzulli, Linda A., Howard Aldrich, and James Moody. 2000. Family matters: gender, networks, and entrepreneurial outcomes, Social Forces 79(2): 523-546.

Rost, Katja, and Bruno S. Frey. 2011. Quantitative and qualitative rankings of scholars. Schmalenbach Business Review 63(January): 63-91.

Schläpfer, Jörg and Olaf Storbeck (2012): BWL-Ranking 2012: Methodik und Zeitschriftenliste, http://www. handelsblatt.com/politik/oekonomie/bwl-ranking/-bwl-ranking-2012-bwl-ranking-2012-methodikund-zeitschriftenliste/6758368.html. Accessed 8 May 2014.

Schrader, Ulf, and Thorsten Hennig-Thurau. 2009. VHB-JOURQUAL2: method, results, and implications of the German academic association for business research's journal ranking. Business Research 2(2): 180-204.

Sugimoto, Cassidy R. 2013. Global gender disparities in science. Nature 504(7479): 211-213.

Tower, Greg, Julie Plummer, and Brenda Ridgewell. 2007. A multidisciplinary study of gender-based research productivity in the World's best journals. Journal of Diversity Management 2(4): 23-32.

van Arensbergen, Pleun, Inge van der Weijden, and Peter van den Besselaar. 2012. Gender differences in scientific productivity: a persisting phenomenon? Scientometrics 93(3): 857-868.

Van Rijnsoever, F.J., and L.K. Hessels. 2011. Factors associated with disciplinary and interdisciplinary research collaboration. Research Policy 40: 463-472.

Vogel, E.E. 1997. Impact factor and international collaboration in Chilean physics: 1987-1994. Scientometrics 38(2): 253-263.

Wuchty, Stefan, Benjamin F. Jones, and Brian Uzzi. 2007. The increasing dominance of teams in production of knowledge. Science 316(5827): 1036-1039.

Xie, Yu., and Kimberlee A. Shauman. 1998. Sex differences in research productivity: new evidence about an old puzzle. American Sociological Review 63(6): 847-870. 